\title{
Evaluation of Die-Attach Bonding Using High-Frequency Ultrasonic Energy for High-Temperature Application
}

\author{
JONG-BUM LEE, ${ }^{1}$ JIE-LI AW, ${ }^{1}$ and MIN-WOO RHEE $^{1,2}$ \\ 1.--Institute of Microelectronics, Agency for Science, Technology and Research (A*STAR ), 11 \\ Science Park Road, Singapore Science Park II, Singapore 117685, Singapore. 2.—e-mail: rheem@ \\ ime.a-star.edu.sg
}

\begin{abstract}
Room-temperature die-attach bonding using ultrasonic energy was evaluated on $\mathrm{Cu} / \mathrm{In}$ and $\mathrm{Cu} / \mathrm{Sn}-3 \mathrm{Ag}$ metal stacks. The In and Sn-3Ag layers have much lower melting temperatures than the base material $(\mathrm{Cu})$ and can be melted through the heat generated during ultrasonic bonding, forming intermetallic compounds (IMCs). Samples were bonded using different ultrasonic powers, bonding times, and forces and subsequently aged at $300^{\circ} \mathrm{C}$ for $500 \mathrm{~h}$. After aging, die shear testing was performed and the fracture surfaces were inspected by scanning electron microscopy. Results showed that the shear strength of $\mathrm{Cu} / \mathrm{In}$ joints reached an upper plateau after $100 \mathrm{~h}$ of thermal aging and remained stable with aging time, whereas that of the $\mathrm{Cu} / \mathrm{Sn}-3 \mathrm{Ag}$ joints decreased with increasing aging time. $\eta-\mathrm{Cu}_{7} \mathrm{In}_{4}$ and $(\mathrm{Cu}, \mathrm{Au})_{11} \mathrm{In}_{9} \mathrm{IMCs}$ were observed at the $\mathrm{Cu} / \mathrm{In}$ joint, while $\mathrm{Cu}_{3} \mathrm{Sn}$ and $(\mathrm{Ag}, \mathrm{Cu})_{3} \mathrm{Sn}$ IMCs were found at the $\mathrm{Cu} / \mathrm{Sn}-3 \mathrm{Ag}$ joint after reliability testing. As $\mathrm{Cu}$-based IMCs have high melting temperatures, they are highly suitable for use in high-temperature electronics, but can be formed at room temperature using an ultrasonic approach.
\end{abstract}

Key words: Transverse ultrasonic bonding, rugged electronics, die-attach bonding, high-temperature storage test, interfacial microstructure

\section{INTRODUCTION}

Nowadays, highly reliable packaging technologies for semiconductor devices that can endure extremely high environmental temperatures are becoming increasingly important in electronic systems for use in oil and gas well logging, automotive, and aerospace industries. In addition, emerging wide-bandgap devices such as those based on silicon carbide ( $\mathrm{SiC})$ and gallium nitride $(\mathrm{GaN})$ frequently need to be operated at higher junction temperatures above $225^{\circ} \mathrm{C}$. This requirement is far beyond the operating limit of conventional silicon (Si)-based devices and the corresponding packaging technologies, which is normally considered to be below $150^{\circ} \mathrm{C}$. Such stringent and demanding requests have led to wide-scale efforts to identify new materials,

(Received October 14, 2013; accepted April 19, 2014;

published online June 7, 2014) at both the device and packaging levels. ${ }^{1}$ To overcome the huge technology gap between conventional packaging and high-temperature-tolerant packaging, it is essential to have full understanding of the thermomechanical, chemical, and metallurgical behaviors of interconnection and packaging materials under target harsh environmental conditions through extensive case studies and in-depth characterization. Electronic packages for use in hightemperature applications should be continuously operated without degradation of performance or reliability. Material degradation, plastic deformation, creep, oxidation, and electromigration are the major failure mechanisms in electronics, and all of these degradation behaviors are normally accelerated by an increase of temperature. Similarly, in metallic bonding parts such as die-attach or flipchip interconnects, the formation and diffusion of intermetallic compounds (IMCs) are also accelerated as the temperature is increased, and these 
layers are easily subject to substantial stress and strain due to the thermal expansion coefficient mismatch between chip and substrate. ${ }^{2}$

In particular, conductive die-attach bonding is the key assembly technology to ensure reliable electrical, thermal, and mechanical connection between functional chips and substrates. Selection and optimization of the bonding method, die-attach material, chip backside metallization, and substrate surface finish are critical to achieve reliable die attachment. Lead-based solders, tin-based lead-free solders, epoxy adhesives, and silver-glass composites are widely used in high-temperature and power electronics applications. ${ }^{3,4}$ However, the recommended continuous operating temperature ranges for these materials are mostly below $200^{\circ} \mathrm{C}$. Therefore, other candidate materials such as transient liquid-phase bonding (TLPB), $\mathrm{Au}-, \mathrm{Bi}-$, and Zn-based solders, and Ag sintering pastes have been extensively researched as die-attach and bonding materials for use in high-temperature applications. ${ }^{1}$ Compared with eutectic high-temperature solder, TLPB offers good characteristics, since the bonding process can be carried out at relatively low processing temperatures while the remelting temperature of the bonded layer can be significantly increased after the bonding layers are fully converted to IMCs through an additional aging process.

However, the commercial thermocompression bonding process for TLPB has some limitations, because it normally requires long bonding times of several minutes. ${ }^{4}$ In addition, there is a strong requirement to identify bonding methods that can generate high-temperature-tolerant joints at low process temperatures to reduce the residual stress induced in electronic packages during the manufacturing process. Similarly, bonding surface cleanliness and roughness have to be controlled to obtain a uniform reaction layer without void formation or trapping.
Considering all the requirements listed above, ultrasonic bonding can be regarded as one of the suitable methods for direct metal-to-metal bonding. Ultrasonic bonding has been proven to form interconnections at low temperature within a very short bonding time, resulting in less stress than conventional reflow or thermocompression bonding processes. ${ }^{5}$ This paper presents feasibility and optimization results for a die-attach process for $\mathrm{Cu} / \mathrm{In}$ - and $\mathrm{Cu} / \mathrm{Sn}-3 \mathrm{Ag}$-based metallic layers using a $60-\mathrm{kHz}$ ultrasonic bonder under room-temperature conditions. The rapid formation of IMC joints and their corresponding failure modes after ultrasonic bonding are also investigated. Die shear testing is used to quantify the bonding strength before and after a high-temperature storage (HTS) test up to $300^{\circ} \mathrm{C}$ and $500 \mathrm{~h}$. Results show that the proposed $\mathrm{Cu} / \mathrm{In}-$ and $\mathrm{Cu} / \mathrm{Sn}-3 \mathrm{Ag}$-based ultrasonic bonding method is applicable for rapid joining of metal-tometal interconnections for die attach. The developed $\mathrm{Cu} / \mathrm{In}$ - and $\mathrm{Cu} / \mathrm{Sn}-3 \mathrm{Ag}$-based TLPB die-attach layers are proven to be reliable and applicable for use in high-temperature electronic packages up to $300^{\circ} \mathrm{C}$.

\section{EXPERIMENTAL PROCEDURES}

The ultrasonic bonding and sample structures used in the evaluation are presented schematically in Fig. 1a, b. The backside of the silicon die was sputtered with $100 \mathrm{~nm} \mathrm{Ti} / 200 \mathrm{~nm} \mathrm{Cu}$, followed by $10 \mu \mathrm{m} \mathrm{Cu}$ electroplating and finally evaporated with $6 \mu \mathrm{m}$ In and $20 \mathrm{~nm} \mathrm{Au}$. On the other hand, ceramic substrates with a $45-\mu \mathrm{m}$-thick electroplated $\mathrm{Cu}$ pad were prepared. Prior to bonding, the surfaces of chips and substrates were sequentially cleaned with $10 \mathrm{vol} \%$ sulfuric acid solution for $30 \mathrm{~s}$ to remove potential contaminants and oxidized layer from the surface. A transverse ultrasonic bonder (SET FC 300 , France) with vibration frequency of $60 \mathrm{kHz}$ was used for direct bonding of chip and substrate at

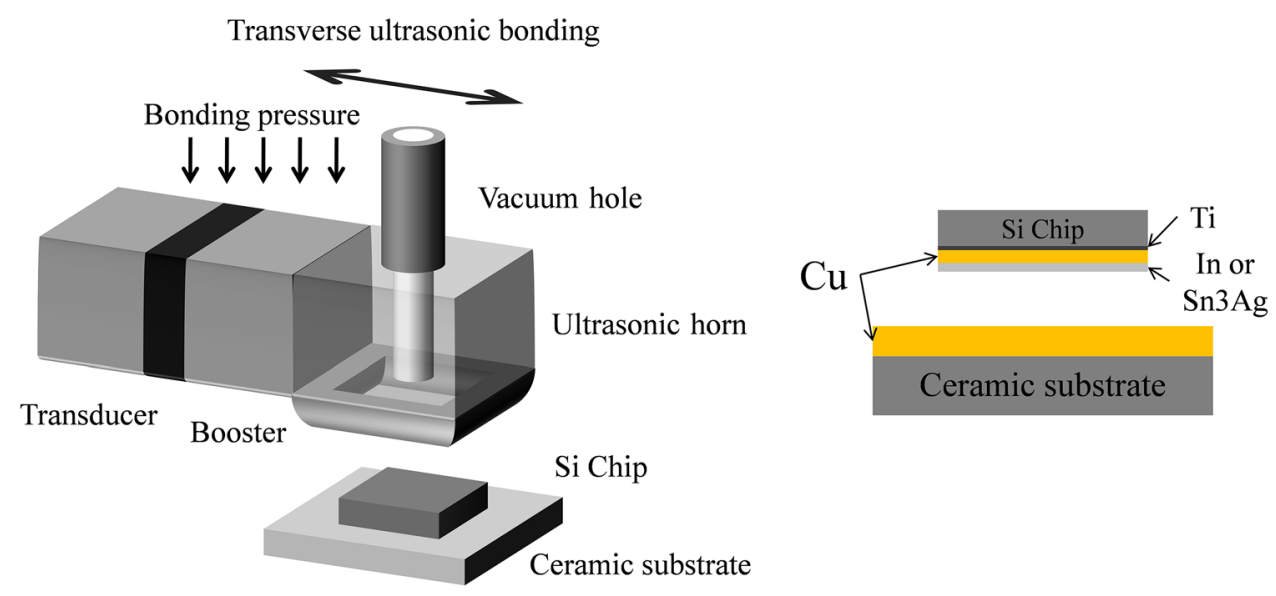

(a)

Fig. 1. Schematic diagrams of (a) transverse ultrasonic bonding system and (b) bonding layer. 
ambient temperature. The process parameters for ultrasonic bonding were bonding power of $4 \mathrm{~W}$ to $60 \mathrm{~W}$, bonding force of $5 \mathrm{MPa}$ to $25 \mathrm{MPa}$, and bonding time of $0.5 \mathrm{~s}$ to $1.5 \mathrm{~s}$. To optimize the bonding condition, bonding strength was evaluated for different bonding conditions using a shear tester (DAGE 5000; Nordson, USA). The displacement rate, probe height, and probe width used for the die shear test were $200 \mu \mathrm{m} / \mathrm{s}, 10 \mu \mathrm{m}$, and $10 \mathrm{~mm}$, respectively. A total of eight bonded samples were prepared for each condition. One sample was used for cross-section, and seven samples were used for die shear testing. The maximum and minimum values of shear strength were eliminated; therefore, five results for the die shear test were used for analysis. The fracture mode of the sheared samples was then analyzed by scanning electron microscopy (SEM). After the dies were assembled using the optimized bonding condition, they were thermally aged at $300^{\circ} \mathrm{C}$ for $100 \mathrm{~h}, 300 \mathrm{~h}$, and $500 \mathrm{~h}$ and subjected to thermal cycle (TC) testing up to 500 cycles

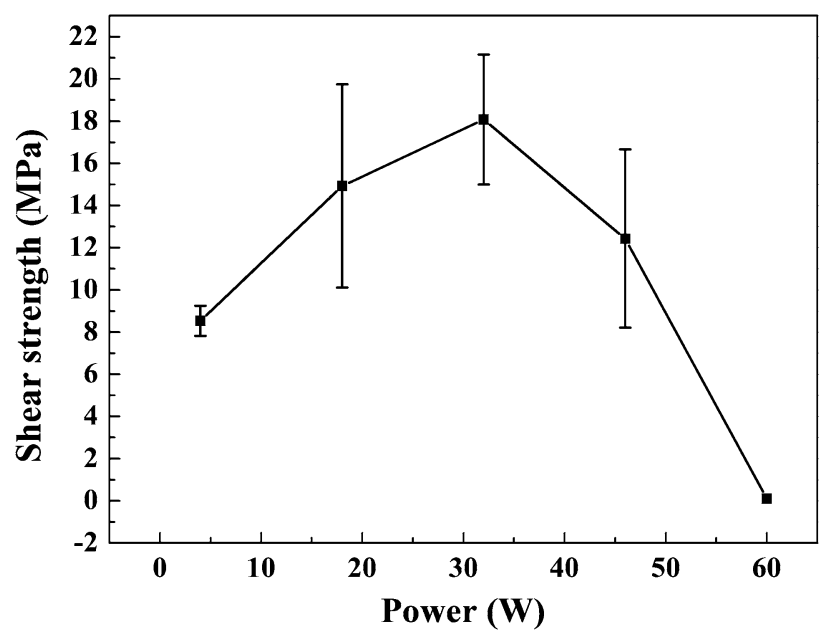

Fig. 2. Die shear strength of ultrasonically bonded $\mathrm{Cu} / \mathrm{In}$ joint versus ultrasonic power. with two temperature set points $\left(-40^{\circ} \mathrm{C}\right.$ and $\left.125^{\circ} \mathrm{C}\right)$ and cycle time of $1 \mathrm{~h}$. At each stage, the die shear test was carried out to investigate the evolution of the shear strength with aging time. Die samples with a 6 - $\mu$ m-thick Sn-3Ag metallized layer prepared by electroplating were also bonded to substrate and subjected to the HTS test as a reference case.

\section{RESULTS AND DISCUSSION}

Dies with $\mathrm{Cu} / \mathrm{In}$ backside metallization as shown in Fig. 1 were bonded using ultrasonic energy to the $\mathrm{Cu}$ surface on the ceramic substrate. The effect of the ultrasonic bonding parameters on the die-attach layer was investigated by measuring the shear strength using the die shear test. Figure 2 shows the effects of the bonding power on the die shear strength of the $\mathrm{Cu} / \mathrm{In}$ joint. The bonding force, time, and temperature parameters were set to $20 \mathrm{MPa}$, $1 \mathrm{~s}$, and $25^{\circ} \mathrm{C}$, respectively, while the ultrasonic power was varied from $4 \mathrm{~W}$ to $60 \mathrm{~W}$. The shear

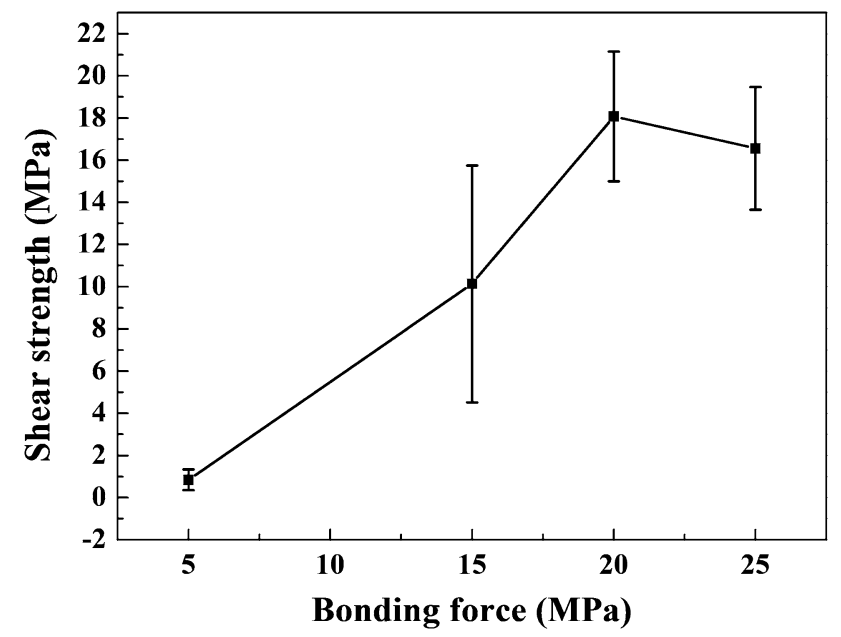

Fig. 4. Die shear strength of ultrasonically bonded $\mathrm{Cu} / \mathrm{In}$ joint versus bonding force.
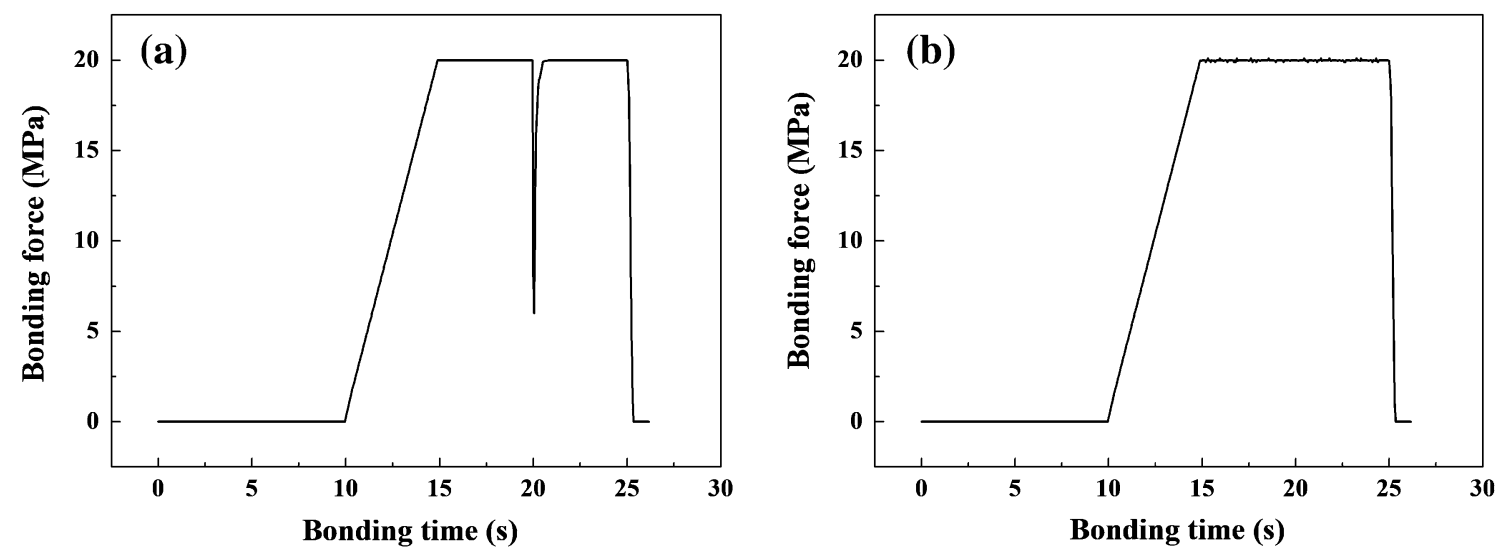

Fig. 3. Bonding force changes during ultrasonic bonding at ultrasonic power of (a) $32 \mathrm{~W}$ and (b) $60 \mathrm{~W}$. 
strength reached a maximum of $18 \mathrm{MPa}$ for bonding power of $32 \mathrm{~W}$, then decreased as the bonding power was increased. This trend shows that insufficient or excessive ultrasonic power can result in low shear strength, while ultrasonic power of $32 \mathrm{~W}$ resulted in the highest shear strength. Bonding force variation could be observed at ultrasonic power of $32 \mathrm{~W}$, while there was no bonding force change at ultrasonic power of $60 \mathrm{~W}$, as shown in Fig. 3. The bonding force drop from $20 \mathrm{MPa}$ to $6 \mathrm{MPa}$ during ultrasonic bonding at ultrasonic power of $32 \mathrm{~W}$ could be caused by the softening effect of the bonding metal layers and partially melted $\mathrm{Cu} / \mathrm{In}$ reaction layer. Larger amplitude and displacement of vibration generally result from excessive ultrasonic power, causing slippage phenomena at bonded joints, misalignment of the chip on the substrate, and thus decreased die shear strength. ${ }^{6}$ Moreover, the ultrasonic horn structure should be designed and fabricated based

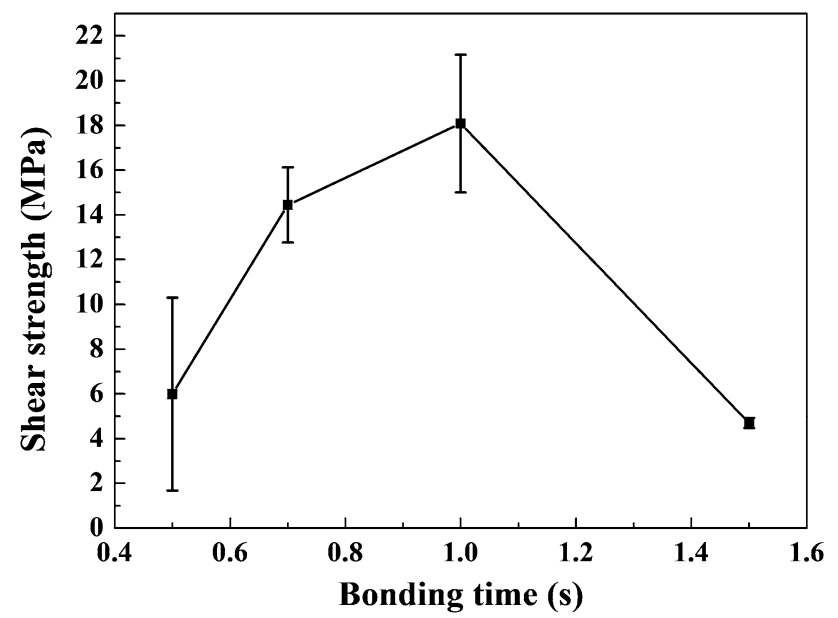

Fig. 5. Die shear strength of ultrasonically bonded $\mathrm{Cu} / \mathrm{ln}$ joint versus bonding time.

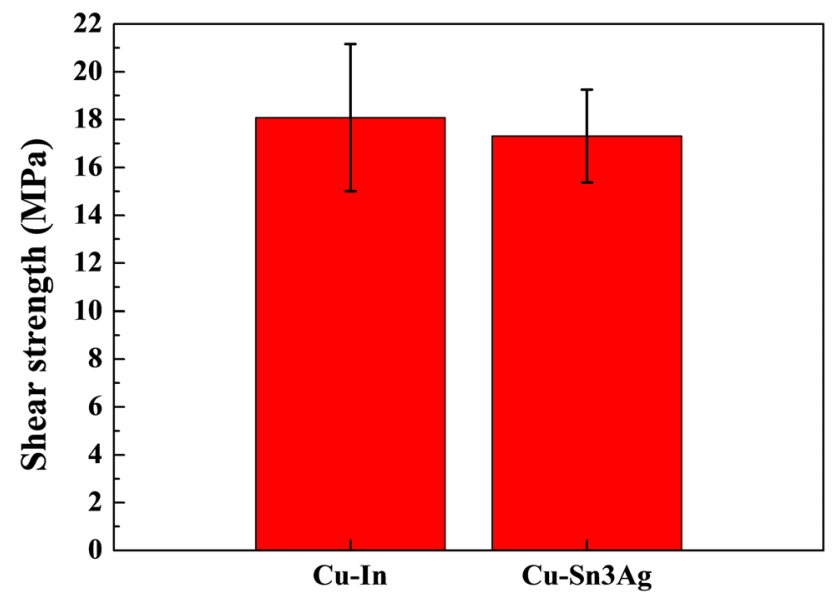

Fig. 6. Comparison of die shear results for $\mathrm{Cu} / \mathrm{ln}$ and $\mathrm{Cu} / \mathrm{Sn}-3 \mathrm{Ag}$ joints. on optimized simulation results. The purpose of this approach is to identify the resonant frequency of the ultrasonic horn, because ultrasonic power beyond this value may not result in good bonding performance. Therefore, a moderate ultrasonic power should be chosen through optimization of the dieattach bonding process.

Figure 4 illustrates the effects of bonding force on the die shear strength of the $\mathrm{Cu} / \mathrm{In}$ joint. The bonding power and bonding time parameters were set at $32 \mathrm{~W}$ and $1 \mathrm{~s}$ while the bonding force was varied. The shear strength increased from $0.8 \mathrm{MPa}$ to $18 \mathrm{MPa}$ with increasing bonding force from $5 \mathrm{MPa}$ to $20 \mathrm{MPa}$. Low shear strength at low bonding force is caused by insufficient frictional heat generation and irregular movement of the ultrasonic horn. ${ }^{7}$

To investigate the effect of the ultrasonic bonding time on the die-attach bonding, the ultrasonic power and bonding force parameters were set at $32 \mathrm{~W}$ and $20 \mathrm{MPa}$, which gave the highest shear strength previously. The ultrasonic bonding time was then varied from $0.5 \mathrm{~s}$ to $1.5 \mathrm{~s}$. Figure 5 presents the results showing the effect of bonding time on shear strength. The shear strength of the bonded joints reached its highest value for bonding time of $1 \mathrm{~s}$, then decreased to $4 \mathrm{MPa}$ when the bonding time was increased to $1.5 \mathrm{~s}$. IMC formation between dissimilar materials is essential for successful joining. Low shear strength is caused by insufficient frictional heat for short bonding time, and higher temperature from frictional heat at the joint interface was generated with increasing bonding time. However, excessive bonding time was accompanied by too much vibration, which will lead to joint breakage.

Test dies with an electroplated Sn-3Ag layer were also prepared to compare their shear strength with the $\mathrm{Cu} / \mathrm{In}$ bonded joint. Both joint systems were bonded using the optimum bonding condition identified ( $32 \mathrm{~W}, 20 \mathrm{MPa}$, and $1 \mathrm{~s}$ ). Figure 6 shows the values of the die shear strength for these joints. The average shear strength of the $\mathrm{Cu} / \mathrm{In}$ joint was not very different from that of the $\mathrm{Cu} / \mathrm{Sn}-3 \mathrm{Ag}$ joint. However, the joints bonded under the optimum condition revealed different fracture surfaces after die shear testing, as shown in Fig. 7. Fully covered dimple structures are observed on the surface of the $\mathrm{Cu} / \mathrm{In}$ joint in Fig. 7a, c. This is believed to be due to the relatively lower reaction temperature between $\mathrm{Cu}$ and In atoms and the greater chance of diffusion between them. The large dimples on the fracture surface could have developed from residual and unreacted In layer. On the other hand, brittle failure is observed on the surface of the $\mathrm{Cu} / \mathrm{Sn}-3 \mathrm{Ag}$ joint in Fig. $7 \mathrm{~b}$, d. $\mathrm{Cu}_{6} \mathrm{Sn}_{5}$ IMC was identified on the surface. Despite the brittle nature of $\mathrm{Cu}_{6} \mathrm{Sn}_{5} \mathrm{IMC}$, it has much better mechanical properties than the solder. This explains why the shear strength of the $\mathrm{Cu} / \mathrm{Sn}-3 \mathrm{Ag}$ joint was still comparable to that of the $\mathrm{Cu} / \mathrm{In}$ joint after bonding, even though 

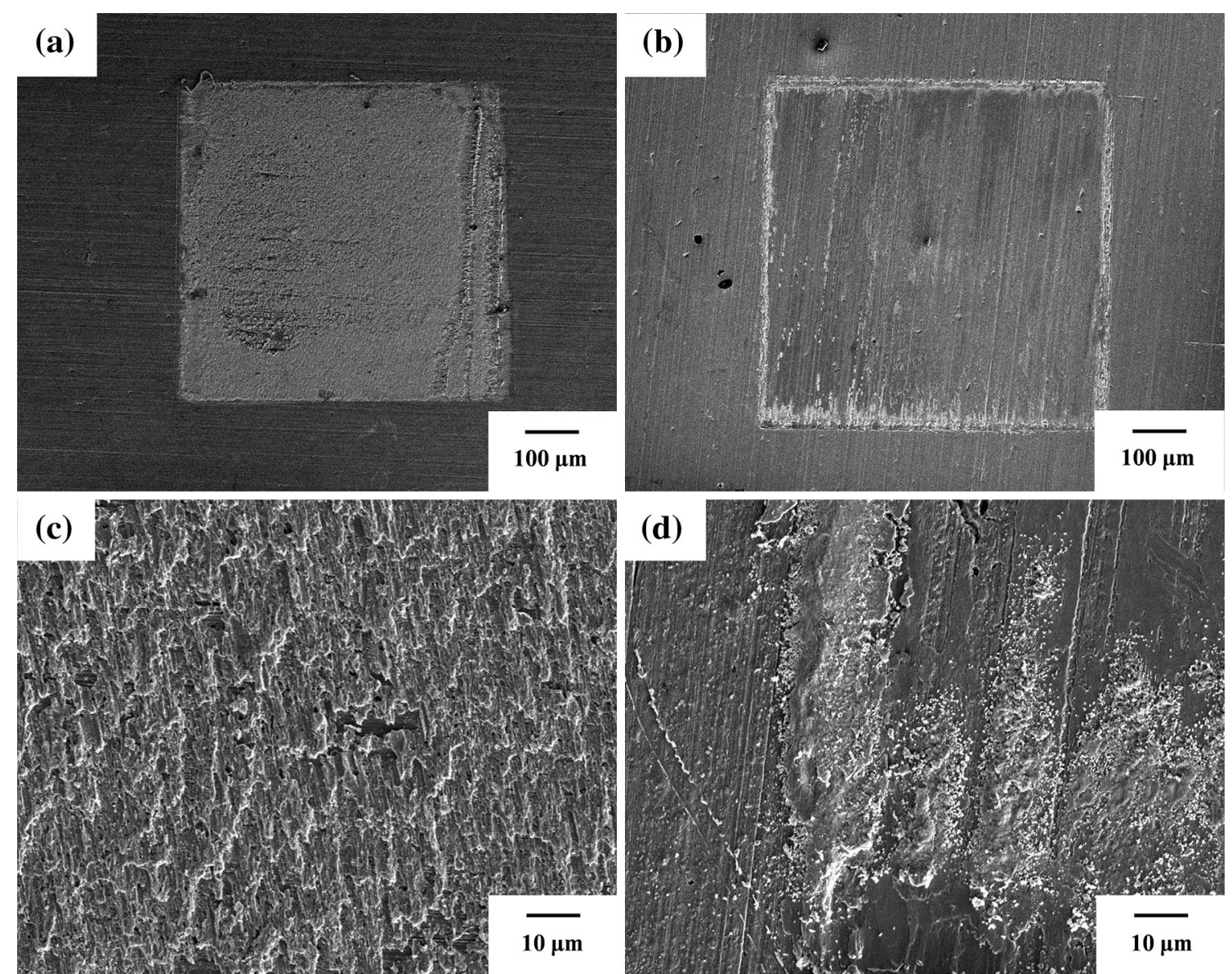

Fig. 7. Fracture surfaces of $(a, c) \mathrm{Cu} / \mathrm{In}$ and $(b, d) \mathrm{Cu} / \mathrm{Sn}-3 \mathrm{Ag}$ joints after die shear test. (c, d) Enlarged images of the fracture surfaces.

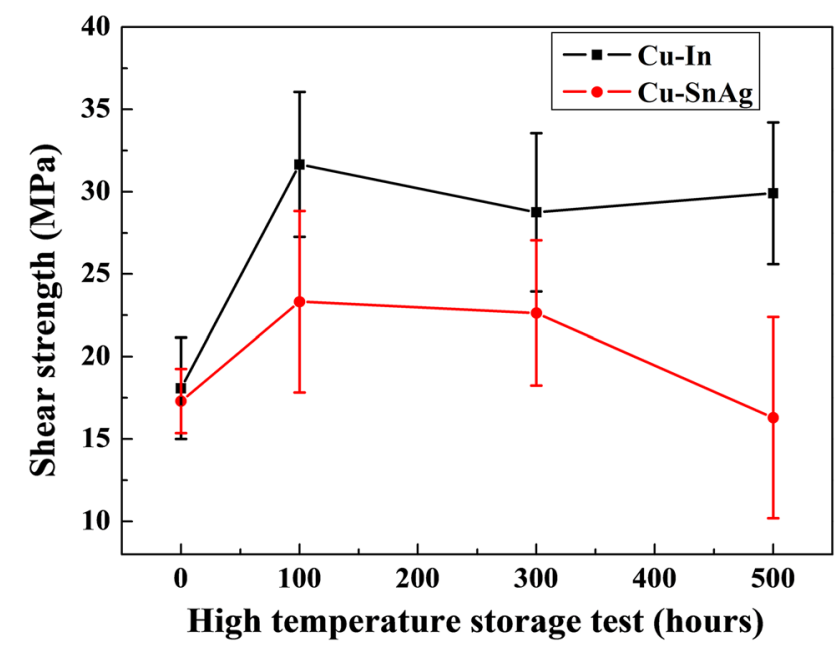

Fig. 8. Variation of shear strength during HTS test for $500 \mathrm{~h}$ at $300^{\circ} \mathrm{C}$.

unreacted solder regions could be found easily on the whole substrate pad.

The In and Sn-3Ag samples attached on the $\mathrm{Cu}$ surface were subsequently aged at $300^{\circ} \mathrm{C}$. The shear test results are shown in Fig. 8. The shear strength of both joint systems increased after $100 \mathrm{~h}$ of storage time. It is believed that the reaction layer of $\mathrm{Cu} / \mathrm{In}$ and $\mathrm{Cu} / \mathrm{Sn}-3 \mathrm{Ag}$ only fully formed IMCs during the HTS aging rather than during the roomtemperature ultrasonic bonding. The shear strength of the $\mathrm{Cu} / \mathrm{In}$ joint saturated after the formation of the full IMC layer at the joint, as can be observed from the data at $300 \mathrm{~h}$ and $500 \mathrm{~h}$. Since the isothermal solidification took place gradually at much lower temperatures than the melting temperatures of the base materials to be joined, there was a great reduction in thermal stress during the HTS test. On the other hand, the shear strength of the $\mathrm{Cu} / \mathrm{Sn}-3 \mathrm{Ag}$ joint decreased as a function of storage time. The failure mode also changed as the aging time was increased. The failure mode at $100 \mathrm{~h}$ of aging was cohesive or die fracture failure, whereas after $500 \mathrm{~h}$ of aging at $300^{\circ} \mathrm{C}$, the failure mode shifted to brittle failure at the interface between the IMC and $\mathrm{Cu}$ surface.

Figure 9 shows cross-sections of $\mathrm{Cu} / \mathrm{In}$ and $\mathrm{Cu} / \mathrm{Sn}$ $3 \mathrm{Ag}$ joints after HTS testing for $500 \mathrm{~h}$ at $300^{\circ} \mathrm{C}$. For the $\mathrm{Cu} / \mathrm{In}$ joint, it can be expected that, if the $\delta-\mathrm{Cu}_{7} \mathrm{In}_{3}$ or $\eta-\mathrm{Cu}_{7} \mathrm{In}_{4} \mathrm{IMC}$ phase is formed during thermal aging, the bond will be thermally stable up to approximately $631^{\circ} \mathrm{C}$. Quantitative SEM/energy-dispersive 
x-ray spectrometry (EDX) point analysis showed In enrichment up to 35 at.\% to 38 at.\% in the dark region and 43 at.\% to 49 at.\% in the bright region. $\mathrm{Au}$ atoms from the 20-nm-thick Au coated on the In layer to prevent oxidation could only be found in the bright region. This suggests formation of $\eta-\mathrm{Cu}_{7} \mathrm{In}_{4}$ and $(\mathrm{Cu}, \mathrm{Au})_{11} \mathrm{In}_{9} \mathrm{IMCs}$, respectively. $\eta-\mathrm{Cu}_{7} \mathrm{In}_{4} \mathrm{IMC}$ is thermally stable up to $631^{\circ} \mathrm{C}$. It is possible to use this $\mathrm{Cu} / \mathrm{In} \mathrm{IMC}$ joint at temperatures up to $400^{\circ} \mathrm{C}$, which is higher than the bonding temperature. The absence of voids, microcracks, and delaminations in the reaction layer indicates that a good bond was obtained. On the other hand, for the $\mathrm{Cu} / \mathrm{Sn}-3 \mathrm{Ag}$ joint, the reaction layer was converted to $\mathrm{Cu}_{3} \mathrm{Sn}$ and $(\mathrm{Ag}, \mathrm{Cu})_{3} \mathrm{Sn}$ IMCs, and there was no $\beta$-Sn region. However, microvoids already generated during ultrasonic bonding were found at the interface between the IMC and $\mathrm{Cu}$ surface. Insufficient ultrasonic energy influenced the formation of unreacted areas because the oxidation layer could not be removed effectively during ultrasonic bonding. The existence of microvoids at the interface is consistent with the die shear testing results.

Figure 10 shows the shear strength results obtained after the die shear test. The shear strength of both joint systems also increased after 100 cycles of TC test with the same mechanism as for the HTS test. There was no degradation of shear strength for the $\mathrm{Cu} / \mathrm{In}$ joint during the TC test, even though the average shear strength of the $\mathrm{Cu} / \mathrm{In}$ joint after the TC test was lower than that after the HTS test. Compared with the result after 100 cycles, the shear strength of the $\mathrm{Cu} / \mathrm{Sn}-3 \mathrm{Ag}$ joint after 500 cycles was decreased by $20 \%$. Nevertheless, the shear strength of the $\mathrm{Cu} / \mathrm{Sn}-3 \mathrm{Ag}$ joint after 500 cycles was still higher than that before the TC test and the minimum value required by MIL-STD-883G.

Figure 11 shows cross-sections of $\mathrm{Cu} / \mathrm{In}$ and $\mathrm{Cu} /$ Sn-3Ag joints after 500 cycles of TC test. For the $\mathrm{Cu} /$ In joint shown in Fig. $11 \mathrm{a}, \eta-\mathrm{Cu}_{7} \mathrm{In}_{4},(\mathrm{Cu}, \mathrm{Au})_{11} \mathrm{In}_{9}$, and In-rich phases were found at the joint interface. In-rich phases remained in the middle of the joint as the peak temperature $\left(125^{\circ} \mathrm{C}\right)$ during the $\mathrm{TC}$ test was lower than the melting temperature of In $\left(156.6^{\circ} \mathrm{C}\right)$. Even though crack propagation through the In-rich phase was observed, there was no degradation of the shear strength after the TC test. The slow diffusion rate between $\mathrm{In}$ and $\mathrm{Cu}$ during the TC test and the repetitive lateral stress allowed the bonding layer to form a crack in the joint interface. Therefore, the highest shear strength after the TC test was lower than that after the HTS test. On the other hand, for the $\mathrm{Cu} / \mathrm{Sn}-3 \mathrm{Ag}$ joint shown in Fig. 11b, cracking or delamination could not be observed at the interface. However, the $\mathrm{Cu}_{6} \mathrm{Sn}_{5}$ phase remained in the middle of the joint, indicating that the transformation of $\mathrm{Cu}_{6} \mathrm{Sn}_{5}$ into $\mathrm{Cu}_{3} \mathrm{Sn}$ phase was still in progress.

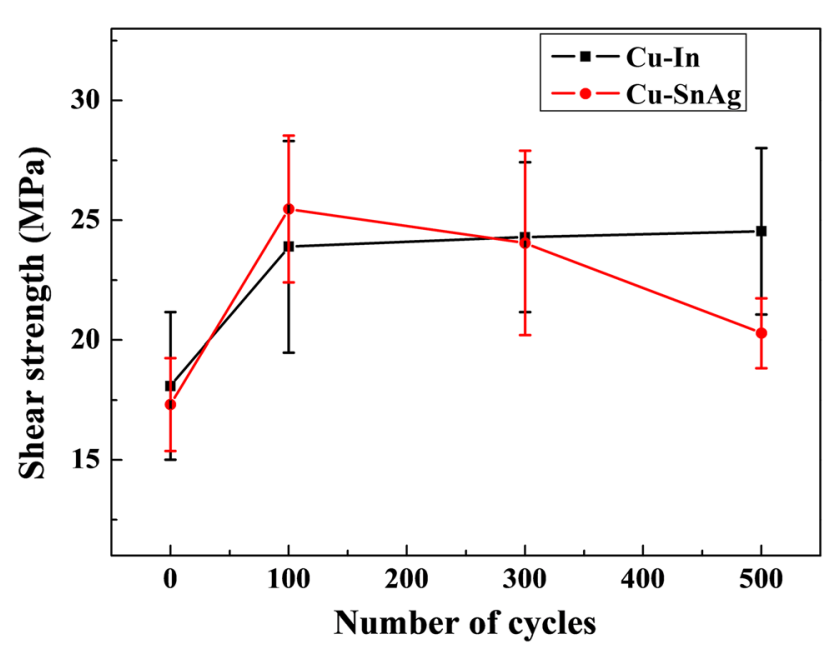

Fig. 10. Variation of shear strength during thermal cycle testing for 500 cycles.
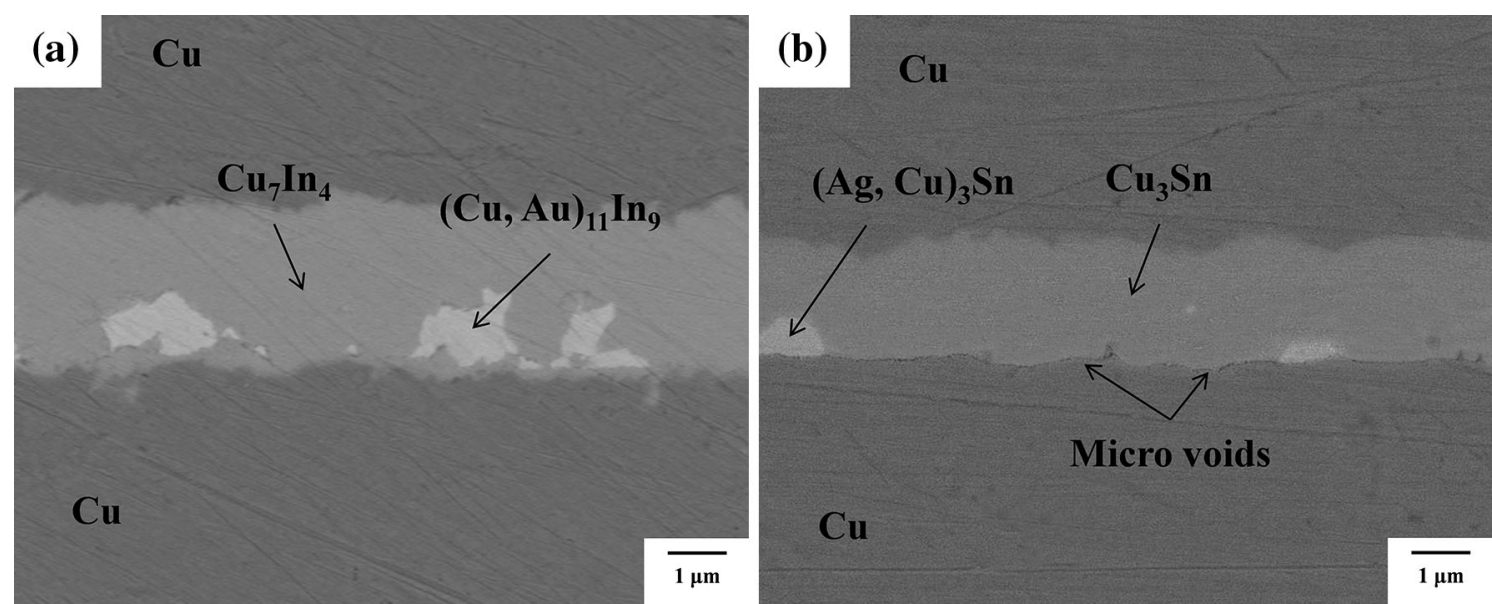

Fig. 9. Cross-sectional SEM images showing (a) Cu/ln and (b) Cu/Sn-3Ag joints after HTS test. 

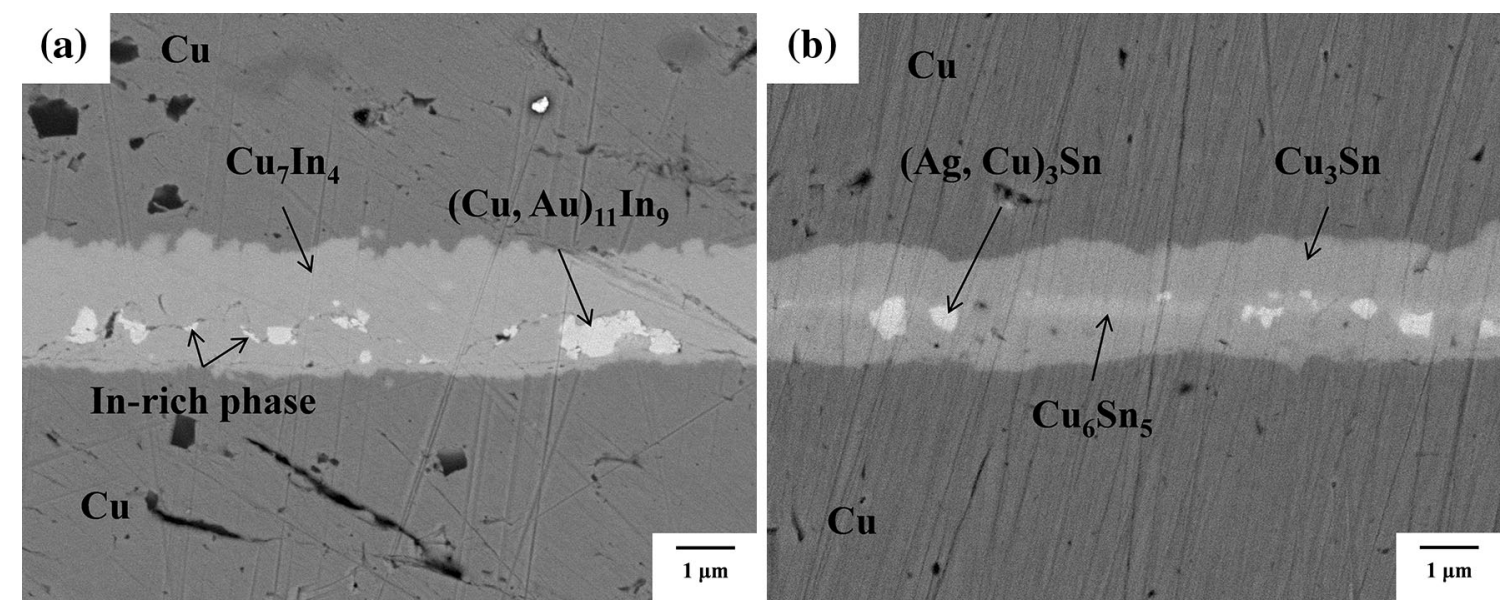

Fig. 11. Cross-sectional SEM images showing (a) Cu/ln and (b) Cu/Sn-3Ag joints after thermal cycle test.

\section{CONCLUSIONS}

$\mathrm{Cu}$ pads on ceramic substrates were successfully bonded to $\mathrm{Cu} / \mathrm{In}$ and $\mathrm{Cu} / \mathrm{Sn}-3 \mathrm{Ag}$ chips using ultrasonic energy at $60 \mathrm{kHz}$. The experimental results revealed that the reaction layer rapidly formed IMC joints at ultrasonic power of $32 \mathrm{~W}$, bonding force of $20 \mathrm{MPa}$, bonding time of $1 \mathrm{~s}$, and ambient temperature. The fracture surface of the $\mathrm{Cu} / \mathrm{In}$ joint after the die shear test showed a dimpled structure, and the bonding interface was fully bonded, whereas for the $\mathrm{Cu} / \mathrm{Sn}-3 \mathrm{Ag}$ joint, brittle failure and unreacted areas were observed. Even though the shear strength of the $\mathrm{Cu} / \mathrm{Sn}-3 \mathrm{Ag}$ joint was similar to that of the $\mathrm{Cu} / \mathrm{In}$ joint, the shear strength decreased with increasing aging time. There were no voids, cracks or delaminations at the $\mathrm{Cu} / \mathrm{In}$ joint after $500 \mathrm{~h}$ of aging time at $300^{\circ} \mathrm{C}$. The $\mathrm{Cu} / \mathrm{In}$ joint obtained by the ultrasonic bonding method at room temperature is confirmed to have sufficient mechanical strength and higher melting point $\left(631^{\circ} \mathrm{C}\right)$ than conventional solder joints, being a promising die-attach technology for electronic packaging applications with extremely high temperatures and harsh environmental conditions.

\section{ACKNOWLEDGEMENTS}

The authors would like to acknowledge the Singapore Science and Research Council (SERC, Grant No. 102165 0081) for financial support through the innovation consortium "Rugged Electronics" program.

\section{REFERENCES}

1. V. Manikam and K.Y. Cheong, IEEE Trans. Compon. Packag. Manuf. Technol. 1, 4 (2011).

2. R.W. Johnson, High Temperature Electronics (New York: Wiley, 1998).

3. R. Kisiel and Z. Szczepanski, Microelectron. Reliab. 49, 6 (2009).

4. N.S. Bosco and F.W. Zok, Acta Mater. 52, 2965 (2004).

5. J. Li, L. Han, J. Duan, and J. Zhong, Appl. Phys. Lett. 90, 242902 (2007).

6. J. Li, J. Duan, and L. Han, Mater. Charact. 58, 2 (2007).

7. J.B. Lee, J.G. Lee, J.L. Jo, J.M. Koo, C.K. Chun, and S.B. Jung, Jpn. J. Appl. Phys. 48, 07GA08 (2009). 